\title{
Crecimiento económico y desarrollo humano en América Latina
}

\section{Gustav Ranis}

Director Henry R. Luce del

Centro de Estudios

Internacionales y de Areas,

Profesor Frank Altschul de

Economía Internacional,

Universidad de Yale

Gustav.ranis@yale.edu

\section{Frances Stewart}

Directora,

Queen Elizabeth House,

Oxford

frances.stewart@queen-

elizabeth-house.oxford.ac.uk
Este estudio explora los nexos recíprocos entre desarrollo humano y crecimiento económico en América Latina. El crecimiento promueve el desarrollo humano a medida que la base de recursos se amplía, en tanto que un mayor desarrollo humano genera más crecimiento a medida que una población más sana y educada contribuye a mejorar el desempeño económico. El análisis de regresión muestra conexiones fuertes que van del desarrollo humano al crecimiento económico en la región, pero aquéllas desde el crecimiento económico al desarrollo humano son mucho más débiles que a nivel mundial, tal vez debido al efecto perturbador de la crisis de la deuda. Según estudios de países exitosos y no exitosos, el éxito en materia de desarrollo humano se debió a un buen desempeño económico combinado con gasto social alto, y los fracasos estuvieron asociados a conflictos, desastres naturales y severas políticas de ajuste. El comportamiento de los países confirmaría la necesidad de dar prioridad al desarrollo humano para alcanzar un ciclo virtuoso de crecimiento y más desarrollo humano. 


\section{I}

\section{Introducción}

Hay poderosas razones para considerar que el objetivo fundamental de la actividad humana es el desarrollo humano y no el crecimiento económico. Se ha definido el desarrollo humano como la ampliación de las oportunidades que tienen las personas de poder acceder a una vida más larga, más saludable y más plena. ${ }^{1}$ Esta definición es muy vasta y puede incluir una gran variedad de opciones, por ejemplo, en cuanto a los aspectos políticos y culturales. En el presente artículo centramos la atención en un limitado subgrupo de opciones, orientadas concretamente a la salud y la educación, que se hallan entre los requisitos fundamentales para tener opciones en otros campos. Este estudio concuerda en gran medida con el espíritu de mucha de la obra de Al Berry, cuya principal preocupación ha sido avanzar más allá del incremento del ingreso per cápita para centrarse en su distribución, con el fin de mejorar las condiciones de vida de los pobres. ${ }^{2}$

En un trabajo anterior (Ranis, Stewart y Ramírez, 2000), examinamos en forma teórica y práctica las vinculaciones entre el desarrollo humano (definido en esta forma más bien restringida) y el crecimiento económico. No hay duda alguna de que existe una firme relación recíproca entre ambos. Por una parte, el crecimiento económico proporciona los recursos que permiten mejorar ininterrumpidamente el desarrollo humano; por la otra, el mejoramiento de la calidad de la mano de obra contribuye de manera importante al crecimiento económico. Si bien es cierto que estos nexos generales se aceptan sin dificultades, para que sean de alguna utilidad en materia de política es preciso conocerlos más a fondo. En especial, hay que saber si existe alguna forma de crecimiento económico que promueva el desarrollo humano, o si determinadas modalidades de crecimiento económico son más propicias para alcanzar el desarrollo humano; igualmente, si hay alguna forma de desarrollo humano que promueva el crecimiento económico o si hay tipos concretos de ese desarrollo más adecuados para promover el crecimiento; $y$ si es posible decir algo útil sobre las prioridades en caso de que haya que optar. Por ejemplo, ¿debería promoverse el desarrollo humano antes que el crecimiento económico, o podríamos postergar el logro del desarrollo humano mientras fomentamos el crecimiento económico?

Para dar respuesta a estas preguntas, exploramos los vínculos teóricos y luego los analizamos empíricamente, basándonos en datos comparados de países de todas las regiones en desarrollo del mundo. El ejercicio nos permitió llegar a resultados convincentes acerca de las interrogantes que acabamos de plantear. En esta oportunidad, nos proponemos examinar en qué medida nuestras conclusiones generales son aplicables en América Latina y qué conclusiones de política han de derivarse de la experiencia de la región.

En la sección II siguiente se resumen los resultados de nuestro trabajo anterior. La sección III contiene algunas estimaciones econométricas para América Latina, y las compara con las conclusiones a que habíamos llegado en el plano mundial. La sección IV da a conocer información sobre algunos países de América Latina que han evolucionado de manera particularmente favorable o desfavorable. Finalmente, la sección $\mathrm{V}$ ofrece algunas breves conclusiones.

\footnotetext{
$\square$ La versión original del presente trabajo fue presentada a la Conferencia en honor al profesor Albert Berry sobre los efectos sociales y económicos de la globalización y de la liberalización en el mercado laboral y la distribución del ingreso, organizada por la Universidad de Toronto y que tuvo lugar el 19 y 20 de abril de 2002. Deseamos expresar nuestro reconocimiento a Tavnett Suri, por el excelente apoyo que nos prestó en la investigación, y a Prateek Tandon, por su ayuda.
}

\footnotetext{
${ }^{1}$ En el primer informe del Programa de las Naciones Unidas para el Desarrollo (PNUD) sobre desarrollo humano se expresa que "El objetivo básico del desarrollo humano es crear un ambiente propicio para que los seres humanos disfruten de una vida prolongada, saludable y creativa" (PNUD, 1990, p. 31) y se define el desarrollo humano como "un proceso en el cual se amplían las oportunidades del ser humano" (ibid., p. 34).

2 Para un ejemplo temprano, véase Berry y Urrutia (1976); para uno mucho más reciente, Berry (ed., 1998).
} 


\section{II}

\section{Desarrollo humano y crecimiento económico: conclusiones del estudio anterior}

A nuestro juicio, el desarrollo humano es el objetivo central de la actividad humana y el crecimiento económico un medio que podría llegar a ser muy importante para promoverlo. Al mismo tiempo, los logros en materia de desarrollo humano pueden contribuir de manera decisiva al crecimiento económico. En consecuencia, hay que examinar dos cadenas causales distintas: una de ellas va del crecimiento económico al desarrollo humano, a medida que los recursos provenientes del ingreso nacional se asignan a actividades que contribuyen a este último; la segunda va del desarrollo humano al crecimiento económico e indica de qué manera el desarrollo humano, aparte de ser un objetivo primordial, contribuye a aumentar el ingreso nacional. Ambas cadenas se muestran en el gráfico 1.

\section{Cadena A: del crecimiento económico al desa- rrollo humano}

Al examinar lo que se ha escrito acerca de los factores que determinan el desarrollo humano, resulta que los principales eslabones de la cadena que va del crecimiento económico al desarrollo humano se relacionan con lo siguiente:

\section{Desarrollo humano y crecimiento económico}

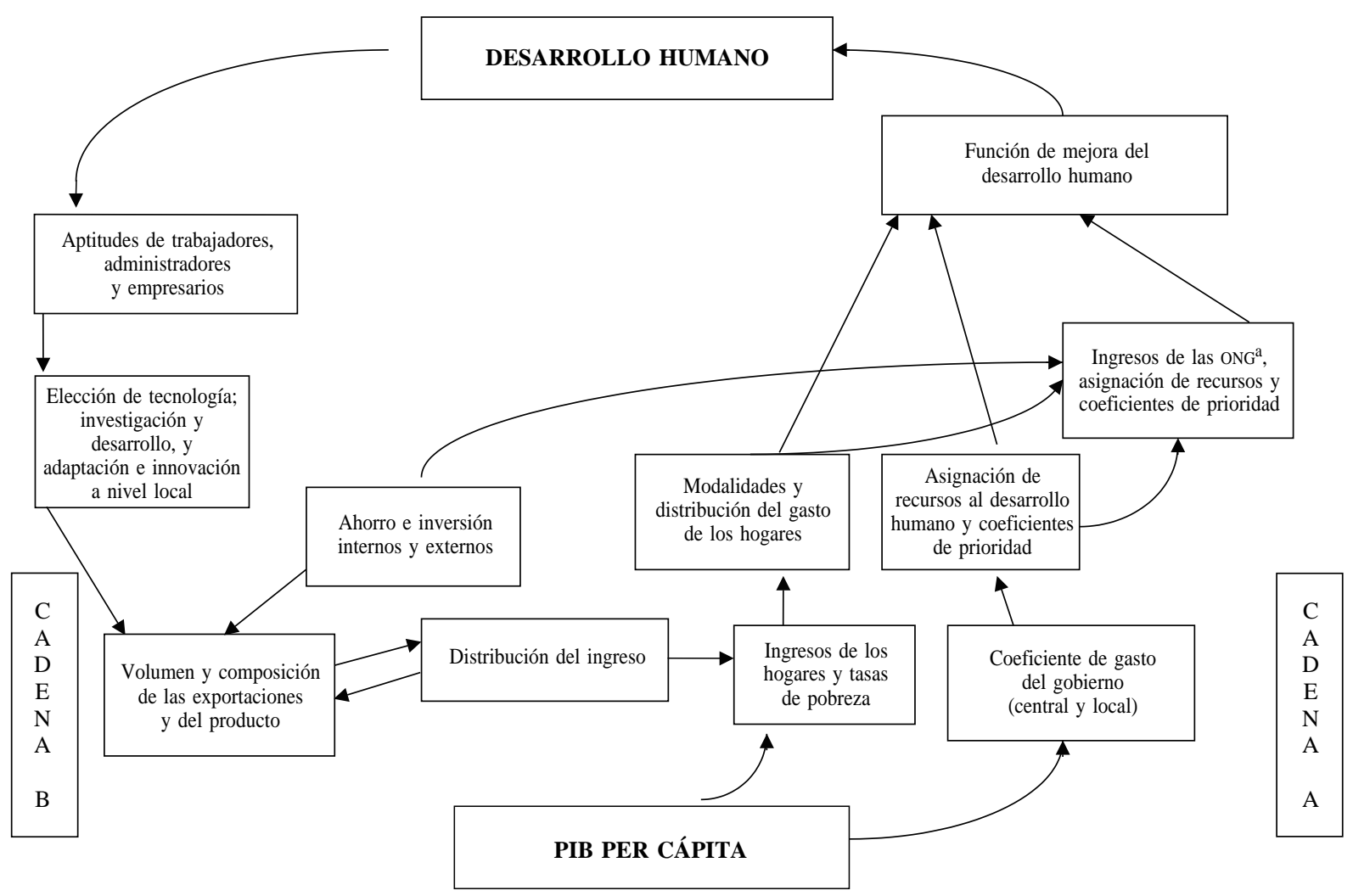

Fuente: Elaboración propia.

a ONG: Organizaciones no gubernamentales. 
a) La distribución del PIB entre los hogares y el gobierno, puesto que cada uno de ellos cumple funciones esenciales, aunque diferentes, en la generación de condiciones favorables al desarrollo humano. A la sociedad civil también le corresponde desempeñar un papel, por ejemplo, por conducto de las organizaciones comunitarias y otras organizaciones no gubernamentales. La participación de estas organizaciones en los recursos nacionales depende de lo que resuelvan el gobierno y los hogares sobre el monto que hay que asignarles.

b) La distribución del ingreso, puesto que lo más probable es que el ingreso que perciben las familias más pobres refuerce nuestro concepto restringido del desarrollo humano (educación, salud), ya que estos hogares son los que tienen mayores carencias.

c) La tendencia de los hogares a invertir sus ingresos, descontados los impuestos, en rubros que en los países pobres contribuyen más directamente a promover el desarrollo humano, por ejemplo, alimentos, agua potable, educación y salud. Al parecer, uno de los principales factores determinantes es la proporción del ingreso que es controlada por las mujeres.

d) Por lo que toca al gobierno, la asignación de recursos al mejoramiento del desarrollo humano es una función del gasto total del sector público, de la proporción de éste que se destina a los sectores de desarrollo humano, y de la manera en que se distribuye dentro de estos sectores. Esto puede expresarse en la forma de tres coeficientes: ${ }^{3} \mathrm{el}$ coeficiente de gasto público, definido como la proporción del producto nacional bruto que gastan los distintos niveles del gobierno; el coeficiente de asignación de recursos al desarrollo humano, definido como la proporción del gasto total del gobierno que se destina a los sectores vinculados al desarrollo humano, y, finalmente, el coeficiente de prioridad del desarrollo humano, definido como la proporción del gasto total en el sector de desarrollo humano que se destina a "áreas prioritarias”. La definición precisa de lo que es área prioritaria varía según el grado de desarrollo del país, por lo cual este tercer coeficiente resulta más arbitrario y difícil de medir que los otros dos. Sin embargo, dentro de los sectores de salud y edu-

\footnotetext{
${ }^{3}$ Véase PNUD, 1991.
}

cación, hay gastos que son claramente mucho más productivos que otros en cuanto al logro de avances en desarrollo humano. Por ejemplo, generalmente se reconoce que la educación primaria, particularmente en una etapa temprana de desarrollo, influye más en el desarrollo humano que la educación terciaria.

e) Lo más probable es que las actividades de las organizaciones no gubernamentales o de otros sectores de la sociedad civil promuevan el desarrollo humano. La información al respecto es más dispersa pero, al parecer, los gastos de las organizaciones no gubernamentales suelen orientarse marcadamente a objetivos de desarrollo humano (por ejemplo, generar ingresos para los pobres y destinarlos a proyectos relacionados con escuelas, nutrición y salud). En la mayoría de los casos, las organizaciones no gubernamentales desempeñan un papel complementario e incluso secundario, pero en algunos casos - como el Bangladesh Rural Advancement Committee (BRAC) y el Banco Grameen, en Bangladesh; las escuelas Harambee en Kenya, y los Comedores Populares en Perú- parecen constituir una fuente importante de reforzamiento del desarrollo humano (Riddell y otros, 1995).

f) Naturalmente, es importante la eficacia de estos diversos gastos para elevar los niveles de desarrollo humano. Los gastos en insumos del desarrollo humano no constituyen objetivos de por sí, pero son medios para avanzar en diversos aspectos del bienestar básico. Otro eslabón importante de la cadena A es el tipo de medida que resulta más provechosa en un nivel de desarrollo determinado, y de qué manera diferentes combinaciones de medidas provocan un cambio en el desarrollo humano. A este eslabón de la cadena lo hemos denominado función de mejoramiento del desarrollo humano; se asemeja a una función de producción en que relaciona los insumos que se aportan al desarrollo humano, como el gasto público en servicios de salud o agua potable, con el objetivo de desarrollo humano que es lograr un mejoramiento de la salud.

De este análisis de los diversos eslabones de la cadena que va del crecimiento económico al desarrollo humano resulta evidente que, en general, cabría prever la existencia de importantes relaciones de causalidad entre la economía y los logros en materia de desarrollo humano, pero que estas conexiones no son automáticas: la solidez de los eslabones de la ca- 
dena A varía de acuerdo con una amplia gama de factores, incluidas la estructura de la economía, la distribución del ingreso y de los bienes y las opciones de política.

\section{Cadena B: del desarrollo humano al crecimien- to económico}

Cuando se enfoca la atención en la cadena B, comprobamos la existencia de un firme respaldo empírico a la idea de que a medida que las personas se tornan más sanas, mejor alimentadas y más instruidas, contribuyen más al crecimiento económico. Dicho más concretamente, las investigaciones a nivel micro y macroeconómico revelan que:

a) La ampliación de la educación primaria aumenta la productividad de los trabajadores urbanos y rurales. En la agricultura, la educación eleva la productividad de los agricultores que utilizan técnicas modernas y, como era de esperar, no influye tanto en los que utilizan métodos tradicionales. ${ }^{4}$ Además, la educación contribuye de manera importante a la capacidad técnica y al cambio tecnológico en la industria.

b) Se ha demostrado que el mejoramiento de la salud y de la nutrición influye directamente en la productividad de la mano de obra, especialmente entre las personas más pobres. ${ }^{5}$ La morbilidad tiene efectos negativos en la productividad de la mano de obra, cosa que se observa, por ejemplo, en estudios realizados en Ghana y Costa de Marfil (Schultz y Tansel, 1993). En algunos casos, la evidencia indica que la salud y la nutrición influyen aún más en la productividad que la educación formal, pese a que la bibliografía relativa al desarrollo ha hecho mucho más hincapié en el efecto de la educación.

c) La enseñanza secundaria, incluso la técnico-profesional, facilita la adquisición de destrezas y de capacidad de gestión.

d) La enseñanza terciaria contribuye al desarrollo de la ciencia básica, a la selección adecuada de las importaciones de tecnología, a su adaptación al medio nacional y al desarrollo de tecnologías autóctonas.

\footnotetext{
${ }^{4}$ Véase Schultz (1975), Welch (1970), Rosenzweig (1995), Foster y Rosenzweig (1994).

${ }^{5}$ Véase las encuestas en Behrman, 1993 y 1996.
}

e) La enseñanza secundaria y terciaria son elementos fundamentales para el desarrollo de instituciones claves - de gobierno, jurídicas, financieras y otras - todas las cuales son esenciales para el desarrollo económico.

f) Desde el punto de vista macroeconómico, las "nuevas teorías sobre el crecimiento" aspiran a hacer endógeno el progreso técnico con la incorporación de algunos de estos mismos efectos, haciendo hincapié a la vez en la educación, en el aprendizaje con la práctica y en investigación y desarrollo. Varios estudios empíricos han mostrado que la educación tiene efectos positivos en el crecimiento a nivel macroeconómico, los que varían según el grado de instrucción y el modelo de crecimiento macroeconómico elegido. ${ }^{6}$

g) La educación afecta la naturaleza y el crecimiento de las exportaciones que, a su vez, influyen en la tasa global de crecimiento. Se ha sostenido que en una fábrica moderna, incluso los trabajadores no calificados normalmente necesitan los conocimientos básicos de letras y aritmética y la disciplina que se adquieren en la enseñanza primaria y el primer nivel de la enseñanza secundaria (Wood, 1994). Hay estudios que han demostrado que el incremento de las exportaciones de manufacturas está directamente relacionado con el crecimiento del Producto Interno Bruto (PIB). ${ }^{7}$

h) La educación también puede influir en el incremento del ingreso per cápita a través de sus efectos en el denominador, esto es, en el aumento de la población. Muchos estudios han mostrado que la escolaridad femenina está inversamente relacionada con la fecundidad (Ainsworth, Beegle y Nyamete, 1995).

i) Se ha demostrado que ampliar la enseñanza primaria conduce a una distribución más equitativa del ingreso (Psacharopoulos y otros, 1992, p. 48), y estudios recientes indican que la distribución más equitativa de bienes e ingresos contribuye al crecimiento económico. ${ }^{8} \mathrm{Al}$ igual que en la cadena $\mathrm{A}$, en la cadena $\mathrm{B}$ la solidez de los diversos eslabones es variable y no hay una conexión automática entre el mayor grado de desarrollo humano y el incremento del PIB per cápita. Naturalmente,

\footnotetext{
${ }^{6}$ Por ejemplo, Barro (1991) y Barro y Lee (1993 a y b).

${ }^{7}$ Entre otros, Michaely (1977), Krueger (1978), Ram (1985), Rana (1988) y Edwards (1993).

8 Véase Alesina y Rodrik (1994), Alesina y Perotti (1994), Persson y Tabellini (1994) y Birdsall, Ross y Sabot (1995).
} 
la educación, la salud y la nutrición no pueden por sí solas transformar la economía. El volumen y calidad de la inversión interna y externa, junto con el entorno general de políticas, son también factores importantes que determinan el desempeño económico. Tal como en la cadena $\mathrm{A}$, en la cadena $\mathrm{B}$ la distribución del ingreso parece ser importante.

\section{Resultados empíricos}

En nuestro trabajo empírico anterior utilizamos regresiones comparadas que abarcaron entre 35 y 76 países en desarrollo, según los datos disponibles sobre determinadas variables para el período 1960-1992. Pusimos a prueba las hipótesis que se indican a continuación, derivadas del análisis de la cadena $\mathrm{A}$ antes resumido. El desarrollo humano sería mayor:

A1: mientras mayor fuera el crecimiento económico; A2: mientras menor fuera la proporción de la población que se encontrara por debajo de la línea de la pobreza; para un determinado nivel de PIB per cápita, esto significaría que el desarrollo humano sería mayor mientras más equitativa fuera la distribución del ingreso;

A3: mientras más ingresos destinaran los hogares al desarrollo humano en un determinado nivel de ingresos. Esto puede relacionarse a la vez con la escolaridad de las mujeres y con el grado de control que ellas ejercieran sobre los ingresos del hogar;

A4: mientras mayor fuera la proporción del PIB que el gobierno destinara al gasto social.

Utilizando como variable dependiente para el período 1970-1992 la variación del desarrollo humano, representada por la reducción del déficit de esperanza de vida, en el caso de la cadena A encontramos que:

a) El crecimiento del PIB per cápita resultó ser significativo y bastante sólido en todas las ecuaciones, y el mayor crecimiento del ingreso per cápita se tradujo en un mejor comportamiento del desarrollo humano. De acuerdo con una ecuación, se estimó que el aumento de un punto porcentual en la tasa media de crecimiento del PIB per cápita reducía en más de tres puntos porcentuales el déficit de esperanza de vida en el período.

b) La proporción de recursos nacionales destinados a gasto social casi siempre resultó ser significativamente positiva. Por cada punto porcentual de incremento de la proporción media del PIB invertida en salud y educación (retrasada), el déficit de esperanza de vida disminuyó alrededor de 1.75 puntos porcentuales.

c) La tasa inicial de matrícula femenina en la enseñanza primaria tuvo un efecto significativo pero pequeño en la tasa de mejoramiento de la esperanza de vida registrada posteriormente. Atribuimos esto a los efectos en el comportamiento del hogar derivados de los ingresos de las mujeres, sus conocimientos y el control que ejercían dentro del hogar.

d) Contrariamente a lo previsto, la distribución más equitativa del ingreso no pareció influir en el desarrollo humano.

e) Tal como cabía esperar, las variables ficticias, tanto para África como para América Latina, resultaron todas negativas y significativas, debido a que el factor de comparación fue la muy exitosa Asia oriental. En cada caso el coeficiente fue bastante pequeño.

Respecto de la cadena B, probamos las siguientes hipótesis:

El crecimiento del PIB sería mayor:

B 1: mientras mayor fuera el desarrollo humano;

B 2: mientras mayor fuera la tasa de inversión;

B 3: mientras más equitativa fuera la distribución del ingreso.

Considerando como variable dependiente el PIB per cápita en el período 1970-1992, en el caso de la cadena $\mathrm{B}$ encontramos que:

a) Las medidas del grado inicial de desarrollo humano eran invariablemente significativas, aunque con coeficientes bajos.

b) Con una sola excepción, la variación de la esperanza de vida (1962-1982) era positiva y significativa.

c) La tasa de inversión interna era siempre significativa, salvo cuando se incluyeron las variables ficticias regionales.

d) Prácticamente todas las variables retrasadas de la distribución del ingreso dieron resultados del signo esperado (esto es, la distribución más equitativa del ingreso iba unida a un mayor crecimiento económico) y casi en todos los casos eran significativas, salvo cuando se incluyeron las variables ficticias regionales.

e) Las variables ficticias regionales correspondientes a América Latina resultaron significativamente negativas en todos los casos, y sucedió lo mismo en un caso correspondiente a África.

En síntesis, consideradas en su conjunto, ambas cadenas mostraron que el crecimiento económico te- 
nía efectos positivos significativos en el desarrollo humano y que, por su parte, este último tenía un efecto significativamente positivo en el crecimiento económico.

\section{Ciclo virtuoso, ciclo vicioso y desarrollo asimétrico}

En consecuencia, los resultados que obtuvimos respaldan decididamente la existencia de dos cadenas que vinculan el desarrollo humano con el crecimiento económico. Esto significa que una economía puede encontrarse en una espiral ascendente de desarrollo humano y crecimiento económico que se refuerzan mutuamente, con niveles altos de desarrollo humano que llevan a un crecimiento elevado, y un alto crecimiento económico que a su vez estimula aún más el desarrollo humano. A la inversa, si el desarrollo humano es precario, puede que conduzca a un crecimiento bajo y, en consecuencia, a un escaso avance hacia el mejoramiento del desarrollo humano.

De acuerdo con este razonamiento, clasificamos el desempeño de los países en cuatro categorías: la de ciclo virtuoso, la de ciclo vicioso y dos categorías de desarrollo asimétrico, una con sesgo pro desarrollo humano (esto es, con fuerte desarrollo humano y escaso crecimiento económico) y otra con sesgo pro crecimiento económico (es decir, con escaso desarrollo humano y marcado crecimiento económico). En el caso del ciclo virtuoso, un buen desarrollo humano refuerza el crecimiento, el que a su vez promueve el desarrollo humano, y así sucesivamente. En el caso del ciclo vicioso, un comportamiento deficiente en materia de desarrollo humano tiende a traducirse en resultados mediocres en cuanto a crecimiento, lo que a su vez reduce los logros de desarrollo humano, y así sucesivamente. Mientras más fuertes sean las vinculaciones en las dos cadenas antes descritas, más pronunciado será el ciclo de crecimiento económico y desarrollo humano, ya sea en sentido ascendente o descendente. Cuando las vinculaciones son precarias, pueden producirse casos de desarrollo asimétrico. Por una parte, puede suceder que un crecimiento económico propicio no traiga consigo un desarrollo humano satisfactorio si, por ejemplo, hay conexiones débiles, como un bajo coeficiente de gasto social; por otra parte, es posible que un desempeño satisfactorio en materia de desarrollo humano no genere un crecimiento económico favorable si hay escasez de recursos complementarios (tasas de inversión bajas, por ejemplo). Sin embargo, lo más probable es que estos casos de desarrollo asimétrico no persistan; con el tiempo, la parte débil actuará como freno sobre la otra y se producirá un ciclo vicioso; o bien, si a lo largo del tiempo se fortalecen las vinculaciones, quizá mediante una modificación de las políticas, habrá un ciclo virtuoso.

Para clasificar empíricamente el comportamiento de los países, comparamos los resultados de cada cual con el promedio de todos los países en desarrollo. Es importante examinar la forma en que los países pasan de una categoría a otra a lo largo del tiempo. En nuestro trabajo anterior, las dos categorías de desarrollo asimétrico resultaron ser muy poco permanentes. En realidad, la conclusión más interesante de este trabajo fue que ninguno de los países que comenzó con un sesgo pro desarrollo económico pudo pasar de allí a un ciclo virtuoso; todos ellos volvieron a caer en el ciclo vicioso (desarrollo humano deficiente, escaso crecimiento económico). En consecuencia, nuestro análisis anterior de alcance mundial reveló que no se puede avanzar a un ciclo virtuoso si hay sesgo en favor del crecimiento económico, ya que ello conduce a un punto muerto. En cambio, algunos países que comenzaron con un sesgo pro desarrollo humano efectivamente lograron avanzar hasta situarse en el grupo de ciclo virtuoso.

\section{III}

\section{El panorama latinoamericano}

El panorama mundial, ampliado ahora al período 19602000, se presenta en el gráfico 2, donde la línea divisoria vertical representa la reducción media del déficit de desarrollo humano del mundo en desarrollo en su conjunto, mientras que la línea divisoria horizontal representa la tasa media de crecimiento del PIB per cápita — ambas ponderadas por la población. Dicho gráfico revela que los países de América Latina se concentran en los cuadrantes de sesgo pro desarrollo humano y de ciclo vicioso. El contraste es marcado con 


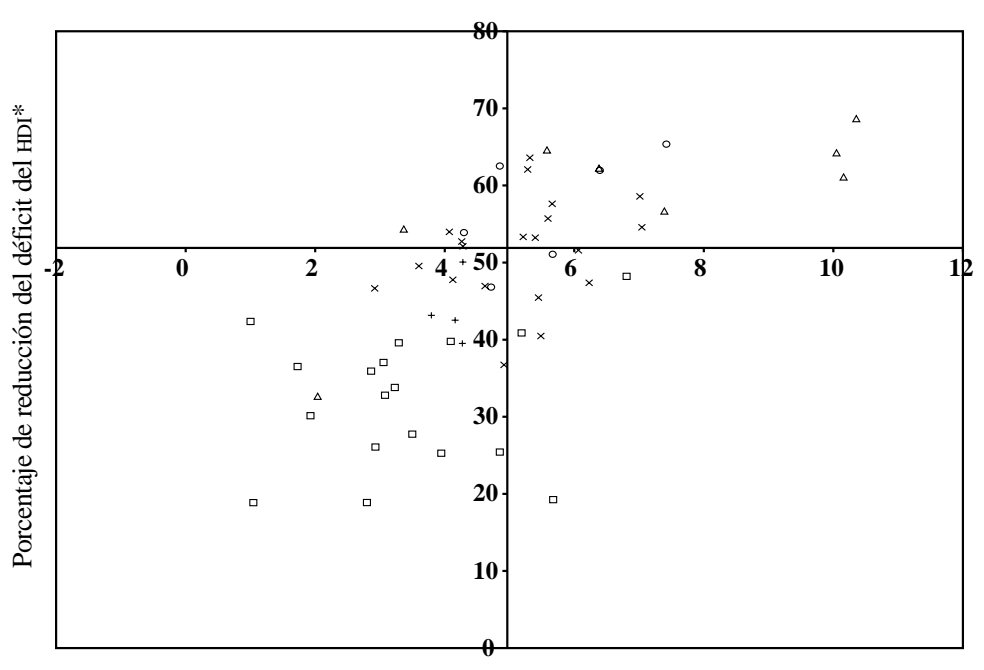

Porcentaje de crecimiento del PIB anual per cápita (1960-2000)

$\square$ Africa OMedio Oriente $\triangle$ Asia Oriental $\times$ América Latina + Asia Meridional

Fuente: Elaboración propia.

los países de Asia oriental, que se sitúan principalmente en el cuadrante de ciclo virtuoso, y los del África subsahariana, que se encuentran sobre todo en el cuadrante de ciclo vicioso. La medida de desarrollo humano que hemos utilizado en el gráfico —esto es, HDI*-, es idéntica a la última fórmula adoptada por el Programa de las Naciones Unidas para el Desarrollo (PNUD) para su propio índice de desarrollo humano (HDI), ${ }^{9}$ salvo que no considera el componente de ingreso, porque no queremos que éste aparezca como parte a la vez del desarrollo humano y del crecimiento económico.

El lugar que ocupa América Latina frente a otras regiones obedece en parte a las repercusiones particularmente intensas que en ella tuvo la crisis de la deuda de los años ochenta. Como se sabe, a menudo se habla de este período como de "la década pérdida". En cambio, cuando la comparación se hace entre países latinoamericanos — particularmente en el decenio de 1980 - se observa que el crecimiento negativo fue la

\footnotetext{
${ }^{9}$ El HDI, según está constituido actualmente, incluye la esperanza de vida al nacer, calculada como índice con un mínimo de 25 y un máximo de 85 años; un componente de educación integrado por el alfabetismo de adultos, una tasa bruta combinada de la matrícula primaria, secundaria y terciaria, y una medida del ingreso real ponderado por el nivel de ingreso, a paridad de poder adquisitivo (véase PNUD, 2001).
}

norma en esa década y que un país como México, cuyo ingreso per cápita en los años ochenta fue decreciente, puede no obstante figurar en el cuadrante de ciclo virtuoso.

Al comparar entre ellos a países de América Latina en 1960-2000, clasificados únicamente en relación con el desempeño medio de la región (gráfico 3), cuatro países aparecen en la categoría de ciclo virtuoso, a saber, Chile, Costa Rica, México y Panamá. El número mayor de países latinoamericanos se sitúa en el cuadrante de ciclo vicioso, y un número reducido en los cuadrantes de sesgo pro desarrollo humano o pro crecimiento económico.

Una vez más, resulta esclarecedor examinar los movimientos de los países en el tiempo. El cuadro 1 muestra las posiciones de los países latinoamericanos decenio por decenio. Los hemos clasificado según su crecimiento y la reducción del déficit del HDI* en cuadrantes de ciclo vicioso, de ciclo virtuoso, de sesgo pro desarrollo humano y de sesgo pro crecimiento económico, y examinamos la forma en que los países cambian de categoría de un decenio a otro. Tales transiciones se determinan por el desempeño de estos países en relación con el promedio de América Latina, no del mundo. Comprobamos que las posiciones de los países fluctúan en el tiempo debido a una serie de razones, tanto generales como específicas de cada cual. 
GRAFICO 3

América Latina: clasificación del comportamiento de los países, 1960-2000

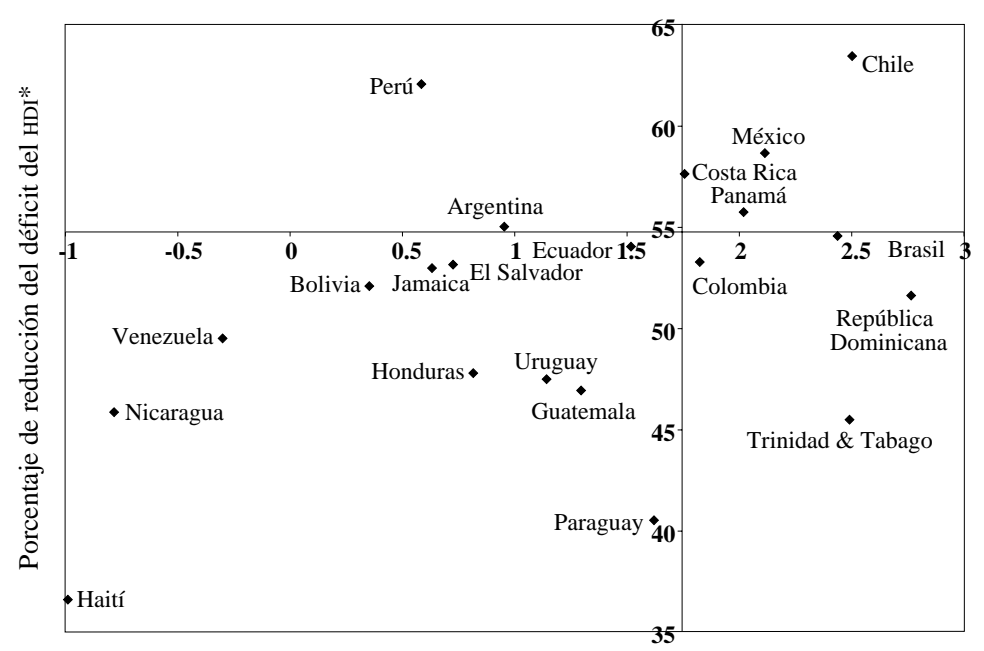

Tasa media de crecimiento del PIB per cápita

Fuente: Elaboración propia.

CUADRO 1

América Latina: Clasificación de los países según las variaciones del desarrollo humano (DH) y el crecimiento económico (CE), 1960-2000

\begin{tabular}{|c|c|c|c|c|}
\hline País & 1960-1970 & $1970-1980$ & 1980-1990 & $1990-2000$ \\
\hline Argentina & Sesgo pro DH & Sesgo pro $\mathrm{DH}$ & Sesgo pro $\mathrm{DH}$ & Ciclo virtuoso \\
\hline Bolivia & Ciclo vicioso & Ciclo vicioso & Ciclo vicioso & Ciclo vicioso \\
\hline Brasil & Sesgo pro CE & Sesgo pro CE & Sesgo pro CE & Ciclo vicioso \\
\hline Chile & Sesgo pro $\mathrm{DH}$ & Sesgo pro $\mathrm{DH}$ & Ciclo virtuoso & Ciclo virtuoso \\
\hline Colombia & Sesgo pro DH & Sesgo pro $\mathrm{DH}$ & Ciclo virtuoso & Sesgo pro DH \\
\hline Costa Rica & Sesgo pro DH & Sesgo pro $\mathrm{DH}$ & Ciclo virtuoso & Ciclo virtuoso \\
\hline Ecuador & Ciclo vicioso & Sesgo pro CE & Ciclo virtuoso & Sesgo pro $\mathrm{DH}$ \\
\hline El Salvador & Ciclo vicioso & Ciclo vicioso & Ciclo vicioso & Sesgo pro CE \\
\hline Guatemala & Ciclo vicioso & Ciclo vicioso & Ciclo vicioso & Ciclo vicioso \\
\hline Guyana & - & Sesgo pro $\mathrm{DH}$ & Sesgo pro $\mathrm{DH}$ & Ciclo virtuoso \\
\hline Haití & Ciclo vicioso & Ciclo vicioso & Ciclo vicioso & Ciclo vicioso \\
\hline Honduras & Ciclo vicioso & Ciclo vicioso & Ciclo vicioso & Ciclo vicioso \\
\hline Jamaica & Ciclo virtuoso & Sesgo pro $\mathrm{DH}$ & Ciclo virtuoso & Sesgo pro $\mathrm{DH}$ \\
\hline México & Ciclo virtuoso & Ciclo virtuoso & Ciclo virtuoso & Ciclo virtuoso \\
\hline Nicaragua & Sesgo pro CE & Ciclo vicioso & Ciclo vicioso & Ciclo vicioso \\
\hline Panamá & Ciclo virtuoso & Sesgo pro $\mathrm{DH}$ & Sesgo pro $\mathrm{DH}$ & Ciclo virtuoso \\
\hline Paraguay & Sesgo pro DH & Ciclo virtuoso & Ciclo virtuoso & Sesgo pro $\mathrm{DH}$ \\
\hline Perú & Ciclo vicioso & Ciclo vicioso & Ciclo vicioso & Ciclo virtuoso \\
\hline República Dominicana & Ciclo vicioso & Sesgo pro CE & Sesgo pro CE & Sesgo pro CE \\
\hline Trinidad y Tabago & Ciclo virtuoso & Ciclo virtuoso & Sesgo pro $\mathrm{DH}$ & Ciclo virtuoso \\
\hline Uruguay & Sesgo pro DH & Sesgo pro $\mathrm{DH}$ & Ciclo virtuoso & Ciclo virtuoso \\
\hline Venezuela & Sesgo pro DH & Sesgo pro $\mathrm{DH}$ & Sesgo pro $\mathrm{DH}$ & Sesgo pro $\mathrm{DH}$ \\
\hline
\end{tabular}

Fuente: Banco Mundial (2001).

Los países de América Latina entran y salen de las categorías de desempeño virtuoso y vicioso con mayor frecuencia que la observada en el contexto mundial. Esto obedece en parte a que se trata de un número menor de países y a que la semejanza entre ellos es mayor, lo que significa que incluso variaciones leves pueden conducir a cambios de categoría; y en parte a que es posible que la mayor incidencia de perturbaciones 


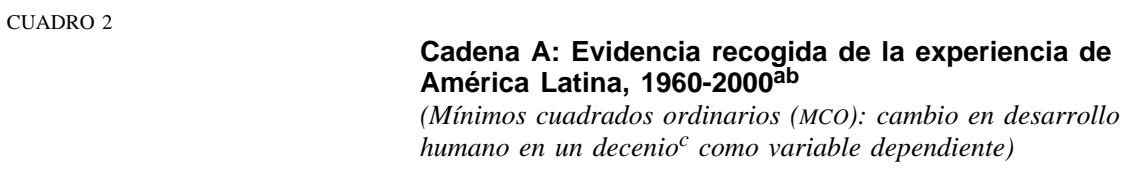


CUADRO 3

Cadena B: Evidencia recogida de la experiencia de

América Latina, 1960-2000

(Mínimos cuadrados ordinarios (MCO): crecimiento del PIB

per cápita en un decenio ${ }^{a}$ como variable dependiente) $)^{b c}$

\begin{tabular}{|c|c|c|}
\hline Variable independiente & (1) & (2) \\
\hline $\begin{array}{l}\text { Tasa de alfabetismo, promedio del decenio } \\
\quad \text { (p. ej. 1970-1980) × } 1000\end{array}$ & $\begin{array}{r}2.54^{\mathrm{d}} \\
(1.92)\end{array}$ & - \\
\hline $\begin{array}{l}\text { Log. de la esperanza de vida, promedio del decenio } \\
\text { (p. ej. 1970-1980) x } 10\end{array}$ & - & $\begin{array}{r}3.94^{\mathrm{d}} \\
(1.80)\end{array}$ \\
\hline $\begin{array}{l}\text { Promedio inversión interna bruta (\% del PIB) en el decenio } \\
\quad \text { (p. ej. 1970-1980) x } 1000\end{array}$ & $\begin{array}{c}4.20 \\
(1.05)\end{array}$ & $\begin{array}{c}4.54 \\
(1.14)\end{array}$ \\
\hline Variable ficticia para la década de 1970 x 100 & $\begin{array}{l}-0.45 \\
(0.08)\end{array}$ & $\begin{array}{l}-2.05 \\
(0.36)\end{array}$ \\
\hline Variable ficticia para la década de 1980 x 10 & $\begin{array}{l}-3.39^{\mathrm{e}} \\
(6.10)\end{array}$ & $\begin{array}{l}-3.63^{\mathrm{e}} \\
(6.03)\end{array}$ \\
\hline Variable ficticia para la década de 1990 x 100 & $\begin{array}{l}-8.57 \\
(1.49)\end{array}$ & $\begin{array}{r}-11.53^{\mathrm{d}} \\
(1.75)\end{array}$ \\
\hline Intercepto x 10 & $\begin{array}{l}-0.55 \\
(0.53)\end{array}$ & $\begin{array}{r}-14.80^{\mathrm{d}} \\
(1.72)\end{array}$ \\
\hline Número de observaciones & 84 & 84 \\
\hline $\mathrm{R}^{2}$ & 0.414 & 0.411 \\
\hline
\end{tabular}

Fuente: Banco Mundial (varios años).

a Por ejemplo, 1970-1980.

b El decenio de 1970 es la década omitida.

c Las cifras entre paréntesis son estadísticas absolutas de $t$.

d Indica significación a nivel de $10 \%$.

e Indica significación a nivel de $1 \%$.

cada decenio resultó positivo, y significativamente relacionado con la reducción de dicho déficit. En la columna 2, la matrícula femenina en la enseñanza primaria tiene efectos positivos y significativos en la reducción del déficit en materia de disminución de la mortalidad infantil. Aunque habríamos deseado incluir una variable para la distribución del ingreso, al no disponer de suficientes datos hubiéramos tenido que bajar el número de observaciones a la cuarta parte.

En el caso de la cadena $\mathbf{B}$, encontramos que dos medidas diferentes de los logros en materia de desarrollo humano al comienzo de cada período (la tasa de alfabetismo y el logaritmo de la esperanza de vida) estaban positiva y significativamente relacionadas con el crecimiento del ingreso per cápita (cuadro 3). Cabe destacar que en esta cadena comprobamos que la variable ficticia correspondiente a 1990 era negativa y altamente significativa. Este es un claro efecto de la crisis de la deuda, que indica que en los años ochenta los logros en desarrollo humano no se tradujeron en crecimiento, como sucedió en otros decenios. Además, en las ecuaciones de la cadena B, la variable ficticia para 1999 también resultó significativamente negati- va, lo que podría reflejar el efecto sostenido de la estabilización y el ajuste en el crecimiento.

Considerando los resultados en su conjunto, encontramos que en el contexto latinoamericano la cadena A parece más débil que la cadena B; esto es, si bien el mayor desarrollo humano conduce a más crecimiento en las décadas siguientes, las tasas de crecimiento en América Latina no están significativamente relacionadas con las variaciones en materia de desarrollo humano. Esto puede deberse en parte al gran peso que tuvieron en América Latina - en comparación con nuestros resultados a nivel mundial- la crisis de la deuda y los ajustes consiguientes, que a menudo se hicieron a expensas de los gastos en desarrollo humano. Por lo demás, al parecer las variaciones en el marco de política, específicamente en cuanto a los coeficientes de prioridad y a los factores que determinan la eficiencia de la función de mejora del desarrollo humano, contribuyeron en buena medida a explicar las diferencias de comportamiento de este último. De hecho, la reseña que se ofrece a continuación acerca de la experiencia de determinados países confirma esta conclusión. 


\section{IV}

\section{Éxitos y fracasos en cuanto a desarrollo humano y a crecimiento económico: casos de países}

En esta sección se describe brevemente la experiencia de tres países que tuvieron un buen desempeño (ciclo virtuoso) y tres cuyo desempeño fue deficiente (ciclo vicioso). La idea es dilucidar a qué situaciones y políticas se podrían atribuir estos resultados.

Chile logró desempeñarse bien durante los cuarenta años considerados, en circunstancias que su régimen político y la orientación de sus políticas sufrían cambios radicales.

Desde comienzos del siglo veinte, este país asumió un fuerte compromiso con el desarrollo humano. Ya en 1930, tres cuartas partes de la población adulta sabía leer y escribir (Thorp, 1998). En los años sesenta, y en los primeros años del decenio de 1970, durante el gobierno de Allende, se mantuvieron los avances en el campo del desarrollo humano gracias a generosas inversiones estatales en educación y salud. Hacia fines de los años sesenta, el gasto social ascendía a un $20 \%$ del PIB; la matrícula en la enseñanza primaria abarcaba un $95 \%$ de los niños de 6 a 14 años de edad, y un $81 \%$ de los partos eran atendidos por profesionales de la salud (Raczynski, 1987). El incremento del ingreso per cápita fue modesto ( $1.6 \%$ anual), e igualitario en relación con América Latina en su conjunto, dando lugar a una evolución sesgada en pro del desarrollo humano.

La toma del poder por Pinochet en 1973 presagió cambios radicales en la política económica y social. En la política económica, hubo un marcado viraje hacia la apertura y una reducción del papel del Estado. En los diez años siguientes, esto se tradujo en el estancamiento del ingreso (tras un alza inicial) y en un creciente desempleo, que de $6 \%$ en los años sesenta se elevó a más de $16 \%$ a comienzos de los años ochenta. Sin embargo, parte de los efectos adversos de esta situación en el desarrollo humano se contrarrestó con grandes programas de empleo. La distribución del ingreso empeoró, al punto que en Santiago el coeficiente de Gini se elevó de 0.47 en los años sesenta a 0.51 en el período 1978-1982. ${ }^{11}$ A contar de 1986, la eco-

\footnotetext{
${ }^{11}$ Riveros (1998). Según Berry (ed. 1998, p. 16), entre 1969 y 1978 los datos sobre la distribución del consumo en los hogares del gran
}

nomía se expandió rápidamente (la tasa de crecimiento alcanzó los niveles más altos de toda América Latina), en gran medida estimulada por el incremento de las exportaciones de productos básicos no tradicionales.

Desde los años sesenta Chile contaba con un amplio conjunto de programas estatales de asistencia social en los campos de la seguridad social, la salud y la educación. Además, había acceso universal a los servicios médicos curativos y a programas de atención preventiva para todas las embarazadas, recién nacidos y niños menores de seis años que no tenían acceso a servicios de salud alternativos. En general, estos programas se mantuvieron pese a fuertes reducciones del gasto social global, que entre 1975 y 1990 cayó de 4\% a $2 \%$ del PIB. Pese a esta baja, en general el desarrollo humano del país siguió mejorando, sobre todo gracias a una mejor focalización, en parte lograda por descentralización de los servicios. En el campo de la educación, el gasto público se centró en la enseñanza primaria y secundaria y se apartó de la terciaria; de hecho, en esta última bajó de $38 \%$ del gasto público total en educación en 1980, a 19\% en 1990. Además, el gobierno creó una serie de programas y subsidios especiales destinados a proteger a los miembros más vulnerables de la sociedad, en especial madres e hijos. Entre ellos cabe mencionar el subsidio familiar al grupo de pobreza extrema, un programa complementario de alimentación para las madres y los preescolares, así como programas para los niños con déficit nutricional, y un programa de alimentación escolar que tenía por objeto reducir la deserción escolar y la tasa de repetición (Raczynski, 1987). En las escuelas públicas, la tasa de deserción escolar bajó de $7 \%$ en 1977 a 5\% en 1984. La entrega de los servicios de salud a los municipios significó tener que destinar el menor presupuesto a la prevención de las enfermedades y no a la medicina curativa. La mortalidad infantil se redujo de 73 por cada mil nacidos vivos en 1972 a 17 en 1989.

En consecuencia, los diez primeros años del período de Pinochet no fueron exitosos en lo que se re-

Santiago ponen de manifiesto uno de los mayores deterioros que se hayan registrado estadísticamente en un país en desarrollo. 
fiere a crecimiento económico, pese a lo cual se mantuvieron los avances en desarrollo humano debido a una mejor focalización de un gasto social más reducido; es decir, un marcado mejoramiento del coeficiente de prioridad condujo a una evolución sesgada en pro del desarrollo humano. En los últimos años del régimen se reanudó el crecimiento económico y el país avanzó hacia un ciclo virtuoso.

El regreso a la democracia, en 1990, condujo a una renovada expansión del gasto social y a un crecimiento económico sostenido y algo más equitativo. En los años noventa, Chile creció a una tasa media de $4.5 \%$ al año, tras haber exhibido una de $1.2 \%$ en los años setenta y de $2.1 \%$ en los ochenta; el desempleo disminuyó a niveles bajos y fue posible suspender los programas estatales de empleo; se llevó a cabo una reforma tributaria que hizo más progresivos los impuestos, con lo cual se ayudó a financiar el creciente gasto social, y el gasto en educación y salud se duplicó con creces. De esta manera, en el decenio de 1990 Chile ingresó al ciclo virtuoso, con un mejor desarrollo humano favorecido por un mayor crecimiento y más gasto social. Por su parte, la aplicación de políticas económicas más eficaces, unida a mayores niveles de desarrollo humano, facilitó la expansión sostenida del PIB per cápita.

Al igual que Chile, Costa Rica tiene una larga trayectoria de compromiso con el desarrollo humano. En 1950, su tasa de analfabetismo era de sólo 20\%, mientras que en el conjunto de América Latina superaba el 40\% (Thorp, 1998). La decisión de eliminar las fuerzas armadas, adoptada en 1948, liberó recursos para el gasto social, que se mantuvo sostenidamente en niveles bastante altos, aunque a comienzos de los ochenta fue objeto de recortes. En 1988, la mitad del gasto público volvió a destinarse a salud y educación, asignándose un $30 \%$ de él a áreas prioritarias.

En los años sesenta y setenta el crecimiento fue bastante bueno (5\% a 6\% al año). Un amplio sistema de prestaciones sociales tuvo cobertura casi universal. Costa Rica invirtió casi el 6\% del PIB en educación. Se alcanzó la matrícula universal en la enseñanza primaria, mientras que en la secundaria se elevó a cerca de dos tercios; un $20 \%$ de los jóvenes de 20 a 24 años de edad asistía a la educación superior, y la matrícula masculina y la femenina eran relativamente equivalentes. En los años sesenta, el analfabetismo de adultos se redujo 8 puntos porcentuales; en 1980, sólo el 13\% de los costarricenses mayores de diez años eran analfabetos, y en 1999 esa proporción había bajado a 4.5\%.

En los años sesenta los avances en salud fueron relativamente lentos, pero más adelante se aceleraron.
En 1960, el país destinaba alrededor de 3\% del PIB a gasto en la salud pública, cifra que a fines de los años noventa se había elevado a más de 5\%, en gran parte hacia fines del período. Mientras que en 1960 la esperanza de vida era de 67 años, en 1980 se elevó a 73 años, y a 76 años en el período 1995-2000. Durante los años sesenta, la mortalidad infantil se mantuvo en un nivel bastante elevado: 68 por mil en 1960 y una leve caída a 62 por mil en 1970. Sin embargo, después bajó significativamente a 19 por mil en 1980 y a 12 por mil en 1999.

Las reducciones de que fue objeto el gasto en el sector social costarricense durante la primera mitad del decenio de 1980 afectaron principalmente a las áreas prioritarias, de modo que la proporción del gasto en educación que se destinaba al $40 \%$ de los hogares situados en el tramo inferior de ingreso bajó de $42 \%$ en 1980 a 36\% en 1986. Sin embargo, en la segunda mitad del decenio el gasto social tuvo un repunte. Por otra parte, el salario mínimo se mantuvo, la distribución del ingreso no empeoró y se reanudaron los avances en materia de desarrollo social. Como resultado, el país pudo mantenerse en un ciclo virtuoso.

Los avances logrados por México en el campo del desarrollo humano fueron muy posteriores a los de Chile o Costa Rica. En 1960, más de un tercio de su población adulta seguía siendo analfabeta. México clasifica en la categoría de ciclo virtuoso debido a las mejoras en desarrollo humano y crecimiento económico del período 1960-1999. Pero de todas formas, en cifras absolutas siguió quedando significativamente por debajo de Chile y Costa Rica. Por ejemplo, al finalizar el período indicado, la esperanza de vida era de 67 años, esto es, poco menor que el promedio de América Latina (69 años) y muy inferior a los 75 años alcanzados en Chile y los 77 años logrados en Costa Rica (Thorp, 1998).

Hasta 1970, durante el gobierno de Echeverría, México disfrutó de lo que se denominó "crecimiento con estabilidad", y también avanzó en materia de desarrollo humano. En el decenio de 1970 continuó creciendo, pero con la ayuda de un fuerte endeudamiento y con crecientes desequilibrios fiscales. La economía tuvo un comportamiento vigoroso a fines de los años sesenta y en los setenta, cuando el PIB aumentó en promedio 7\% a nivel global (3\% per cápita), y el sector manufacturero, que era el de mayor crecimiento del país, atrajo un volumen apreciable de inversión extranjera. La pobreza extrema declinó de $76 \%$ en 1960 a 45\% en 1981, aunque la distribución del ingreso siguió siendo insatisfactoria, con coeficientes de Gini de 0.5 a 0.6 (Maddison, 1992). 
Uno de los grandes pilares del gobierno posrevolucionario de México ha sido su resuelto compromiso con el desarrollo humano. En los años sesenta, este compromiso se tradujo en mayor hincapié en la reforma agraria, la salud, el saneamiento, la educación y la nutrición. En los años setenta, el gasto en educación ascendió a un promedio aproximado de $18 \%$ del gasto público total, mientras que el gasto medio en salud fue de 5\% (FMI, varios años). También contribuyeron a estos resultados los adecuados coeficientes de prioridad, en virtud de los cuales el grueso del gasto público se destinó a la enseñanza primaria y a programas de vacunación. Como resultado, entre 1960 y 1980 el desarrollo humano mejoró significativamente; la esperanza de vida aumentó de 59 a 66 años; la mortalidad infantil declinó de 74 a 53 por mil nacidos vivos; el alfabetismo adulto se elevó de $66 \%$ a $83 \%$; y la matrícula escolar bruta casi se duplicó (subió de 106\% a $120 \%$ en la enseñanza primaria, de $23 \%$ a $49 \%$ en la secundaria y de $5 \%$ a $14 \%$ en la terciaria).

En los años ochenta, bajo el acoso de la crisis de la deuda, las cosas fueron diferentes. México disminuyó el coeficiente de gasto, con la consiguiente reducción de las erogaciones en desarrollo humano, que entre 1983 y 1988 se contrajeron 6\% al año. En el mismo período el ingreso real disponible per cápita cayó 5\% y los niveles de desempleo y de subempleo, así como la tasa de pobreza, fueron cada vez mayores. La participación de la educación en el gasto total sufrió una merma de casi 30\%, gran parte de la cual fue absorbida por la enseñanza primaria (Friedmann, Lustig y Legovini, 1995). Entre 1983 y 1988 el número de maestros y alumnos por escuela se redujo, y otro tanto sucedió con el número de consultorios médicos, camas de hospital y médicos per cápita. Sin embargo, pese a sus deficientes resultados en materia de crecimiento económico y desarrollo humano, México lo hizo relativamente bien si se le compara con el resto de la región y no con el ámbito mundial .

Tras las reformas económicas iniciadas a fines del decenio de 1980, la economía mexicana evolucionó mejor, estimulada por la inversión extranjera a que dio lugar la ratificación del Tratado de Libre Comercio de América del Norte. Sin embargo, a raíz de las crisis financieras de 1994 y 1998, se produjo una contracción económica que condujo a reducir la inversión en el sector social. En la década de 1990, en su conjunto, la tasa media de crecimiento fue de $1.25 \%$ al año (en los años ochenta había sido negativa). En la primera parte de los años noventa se elevó la proporción del PIB destinada a los sectores sociales. Entre 1989 y 1993, el gasto en educación aumentó $90 \%$ y, en salud, $79 \%$. Gracias a una focalización mayor, aunque relativamente ineficaz, se redujeron los subsidios generales de alimentación. Para aumentar la eficacia del gasto social en función de su costo y estimular una mayor participación de la comunidad, se creó un amplio programa denominado PRONASOL. Uno de sus componentes contemplaba una gran gama de programas sociales, incluso en educación y salud, pero el partido que a la sazón se encontraba en el poder lo acusó de manipulación política. Es posible que estos factores expliquen por qué en los años noventa México pasó a la categoría de países con sesgo pro crecimiento económico. En 1995, el programa cambió de nombre (PRONOSOL) y fue reestructurado, tornándose menos político.

En síntesis, México estuvo en la categoría de ciclo virtuoso en los años sesenta y setenta debido a su crecimiento económico y gasto social. Otro elemento que ha reforzado el desarrollo humano en el país ha sido el mejoramiento de las funciones de género gracias a la mayor institucionalización de los derechos de la mujer. El hecho de que en los años noventa los resultados en materia de desarrollo humano hayan sido menos favorables tal vez pueda atribuirse a una focalización inadecuada, a los recortes que fue preciso introducir con motivo de las crisis y a la situación heredada del decenio anterior.

Entre 1960 y 1970 , debido a un crecimiento económico acelerado de más de $6 \%$ al año y al vigoroso compromiso del gobierno con el desarrollo humano, Jamaica se encontró en un ciclo virtuoso, con un gasto social que aumentó de 5.6\% del PIB en 1960 a $12.2 \%$ en 1975. En los años sesenta, la matrícula en la enseñanza primaria se elevó de $65 \%$ a $85 \%$, mientras que en la enseñanza secundaria aumentó de $15 \%$ a $58 \%$. En 1970, la esperanza de vida era de 68 años y la tasa de alfabetización de $86 \%$, ambas muy superiores al promedio regional (Thorp, 1998). Sin embargo, graves problemas económicos y la consiguiente aplicación de programas de ajuste duros se tradujeron en un deterioro de los resultados en el campo del desarrollo humano y empujaron a Jamaica hacia un ciclo vicioso por gran parte del resto del período.

En los años setenta, severas perturbaciones de la relación de intercambio originaron una contracción económica que obligó a introducir pronunciados recortes en el gasto social, de acuerdo con las indicaciones del FMI. En los años ochenta se mantuvo el deterioro del gasto en desarrollo humano y se aplicaron rigurosas medidas de ajuste, incluida una reducción de $30 \%$ 
en el gasto real en educación y salud entre 1980 y 1986 (Banco Mundial, 1984). El coeficiente de prioridad del desarrollo humano también empeoró, aunque el gasto en la educación terciaria estuvo relativamente protegido. Los subsidios generales de alimentación fueron reemplazados por otros focalizados, y los niveles de nutrición se debilitaron. Por su parte, la distribución del ingreso se tornó más inequitativa y aumentó la pobreza.

A fines de los años ochenta la economía jamaiquina tuvo un repunte y en el período 1986-1990 el PIB per cápita aumentó $2.4 \%$ al año; pero esto no se tradujo en gasto social, cuya participación porcentual en el PIB disminuyó. Sin embargo, a comienzos de los años noventa dicho gasto se recuperó, al punto que en 1995 el gasto en salud pública se elevó a 3.2\% del PIB y aquél en educación pública llegó a 5.4\%.

En los años noventa, la economía del país siguió teniendo resultados mediocres. El crecimiento medio del PIB per cápita fue negativo (alrededor de $-0.6 \%$ al año entre 1990 y 1999, comparado con $1.2 \%$ en el decenio anterior), pese a lo cual los indicadores de desarrollo humano mejoraron sustancialmente, lo que podría augurar un mejor desempeño futuro en materia de crecimiento económico. Hacia fines del decenio, la esperanza de vida del país era de unos 75 años, la tasa de alfabetismo de adultos de $86 \%$, la tasa bruta de matrícula en la enseñanza primaria de $98 \%$, y en la enseñanza secundaria de $90 \%$. La mortalidad infantil bajó a 20 por mil nacidos vivos.

El caso de Guyana se asemeja al de Jamaica, sólo que más desfavorable, puesto que ya en los años sesenta la precariedad del comportamiento económico menoscabó el desarrollo humano, lo que después se agravó debido a programas de ajuste que incluyeron reducciones del gasto social. En el decenio de 1990 hubo un leve repunte económico, pero éste no se acompañó de una mejora importante del desarrollo humano.

Al comienzo del período, la esperanza de vida del país era relativamente baja, de aproximadamente 60 años en 1960, y la mortalidad infantil elevada, de cerca de 99 por mil. Tras la independencia, en 1966, hubo un período inicial en que el PIB y el gasto social aumentaron de manera significativa. Por ejemplo, en el período 1970-1975 el gasto en educación creció más de $60 \%$ y en salud más de $40 \%$. La tasa de matrícula de la enseñanza primaria y de la enseñanza secundaria se elevaron. En los años setenta, el gobierno amplió sustancialmente su control de la economía, estimándose que dominaba un $80 \%$ del sector formal. La expansión inicial cedió paso a una crisis económica casi permanente, originada por una combinación de factores externos (deterioro de la relación de intercambio) y deficiente gestión interna. Entre 1975 y 1983, la caída del PIB fue mayor que su expansión anterior. A lo largo de los años setenta el crecimiento del PIB per cápita promedió un $0.7 \%$ al año. En los años ochenta persistieron las crisis externas y la inadecuada gestión interna; la absorción del grueso de los sistemas de distribución y comercio minorista por el gobierno se acompañó de grandes bajas de la productividad. El racionamiento de las divisas y el control de las importaciones desembocaron en escasez de insumos productivos, y la precariedad de la infraestructura dificultó aún más la evolución de la economía. En los años ochenta, ésta exhibió un retroceso y el ingreso per cápita se redujo 3.9\% al año. Durante el decenio de 1980, el PIB acumuló una caída de $28 \%$. Además, las crisis condujeron a reducciones del gasto social, el que disminuyó como proporción del gasto total del gobierno. En 1988, el gasto en educación sólo alcanzó a un $6.4 \%$ del gasto total del gobierno y la inversión en salud llegó únicamente a $3.7 \%$.

En el decenio de 1990 se modificó la política macroeconómica cuando el gobierno liberalizó las normas aplicables a las divisas, eliminó los controles de precios y las prohibiciones sobre las importaciones y estimuló la inversión privada. Esto dio lugar a una racha de crecimiento: entre 1990 y 1999 el PIB per cápita creció a una tasa media anual de $4.2 \%$ (muy por encima del promedio regional). No obstante, el desarrollo humano se mantuvo a la zaga, ya que en 1999 la esperanza de vida sólo llegaba a unos 64 años, siendo que el promedio regional era de aproximadamente 70 años, y la mortalidad infantil continuaba siendo elevada, de alrededor de 57 fallecidos por cada mil nacidos vivos (el promedio regional era de 31). Hacia 1990 el gasto público en salud y educación comenzó a mostrar alguna mejora y al finalizar la década el primero se situaba en torno al 9\% del PIB y el segundo se había elevado al $8 \%$ del gasto público total.

En Nicaragua se distinguen tres períodos diferentes: la era de Somoza, que abarcó los años sesenta y setenta; la revolución sandinista y posterior gobierno de este signo, que se acompañó de guerra civil permanente; y el período de posguerra de los años noventa. Nicaragua fue uno de los últimos países de América Latina en lograr algún avance sustancial en materia de desarrollo humano. En 1960, más de la mitad de la población adulta era analfabeta y la esperanza de vida llegaba sólo a 47 años (Thorp, 1998).

Durante la era de Somoza se registraron altas tasas de crecimiento, pero su distribución fue muy 
desigual. Los propios Somoza eran dueños o tenían el control del $60 \%$ de la actividad económica del país. El gasto social, que también estaba desigualmente distribuido, era bajo. Hacia fines del decenio de 1970, sólo un $65 \%$ de los niños en edad escolar estaban matriculados en la escuela y no más de $22 \%$ terminaba los seis años de enseñanza primaria. Tres cuartas partes de la población rural eran analfabetas. La tasa de mortalidad infantil bordeaba los 100 por cada mil nacidos vivos. Entre 1965 y 1975 se duplicó el número de niños menores de cinco años que padecían de malnutrición, en circunstancias de que el PIB también aumentó al doble.

El crecimiento económico se alteró notablemente con la revolución de 1979, año en que el PIB se contrajo un $25 \%$. Los sandinistas se habían comprometido a aumentar el gasto social y mejorar la distribución de los bienes y del ingreso. En los primeros años del régimen, en 1980 y 1981, el PIB se elevó 5\% y hubo una gran expansión del gasto social y de la cobertura de los servicios sociales. Se duplicó la proporción del PIB destinada a la enseñanza primaria y secundaria y el analfabetismo de adultos se redujo de $50 \%$ a $23 \%$. El sector salud también mostró una fuerte expansión y se hizo hincapié en la atención preventiva y primaria, mediante la focalización de los servicios en las principales causas de la mortalidad materno-infantil y de los menores de un año, la ampliación de la cobertura y el logro de una mayor participación de la comunidad. En consecuencia, tanto en salud como en educación los coeficientes de prioridad fueron favorables. El desempeño de ambos sectores registró mejoras: en 1980, la esperanza de vida se había elevado a aproximadamente 59 años (desde 47 años en 1960) y la matrícula bruta en la enseñanza primaria se situaba en torno al $94 \%$ (66\% en 1960).

Sin embargo, a raíz de la guerra civil que sobrevino a continuación, el PIB disminuyó año a año entre 1984 y 1990, acumulando una caída de más de 40\% en el decenio como consecuencia de la actividad bélica, el embargo comercial impuesto por los Estados Unidos y la renuencia a invertir de la banca extranjera. Se produjo una espiral inflacionaria y la situación se agravó debido a desastres naturales, incluidos huracanes y sequía. En 1990, el ingreso per cápita fue inferior al de los años setenta y en la década siguiente el PIB per cápita cayó un $4.1 \%$ al año.

Con el tiempo, el colapso económico y los trastornos causados por la guerra terminaron por debilitar los sectores sociales, pese a los esfuerzos de los sandinistas. Por ejemplo, la tasa de alfabetismo retrocedió a los niveles de fines de los años setenta, y la mortalidad infantil, que en los primeros años de su gobierno había bajado a 63 por mil, comenzó a remontar, hasta alcanzar a 72 por mil en 1989.

En el período de posguerra de los años noventa predominaron los problemas de la deuda y el ajuste, y también los causados por desastres naturales, como una sequía y un huracán. La verdad es que nunca se inició una recuperación económica y que el gasto social se redujo. En el decenio de 1990, la tasa de crecimiento del PIB per cápita fue apenas positiva, situándose en torno al 0.3\% al año en el período 1990-1999.

En síntesis, los años de Somoza ilustran hasta qué punto un crecimiento económico favorable puede no traducirse en desarrollo humano cuando es inequitativo, cuando la distribución del ingreso y los bienes son desiguales, y cuando el gasto social es bajo y se acompaña de un coeficiente de prioridad desfavorable. En cambio, en el período sandinista el desarrollo humano mejoró notablemente al comienzo, porque el gasto social aumentó y se distribuyó mejor, pero ello se anuló por los efectos de la guerra, el embargo y los desastres naturales. En el período de posguerra hubo que hacer frente a la deuda derivada del conflicto bélico, a financiamiento inadecuado y a la aplicación de severas políticas de ajuste.

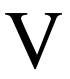

\section{Algunas conclusiones}

En comparación con el promedio general del mundo en desarrollo, en el período1960-2000 América Latina en su conjunto se caracterizó por niveles relativamente altos de desarrollo humano y de avances en este campo, pero por comportamientos menos favorables en materia de crecimiento económico. En 1960, a comien- zos del período, la esperanza de vida de América Latina era bastante superior a la del resto del mundo en desarrollo. Es posible que esto se haya debido a que la región alcanzó la independencia política mucho antes y por lo tanto hubo un mayor compromiso con el desarrollo humano, en especial por parte de las elites. Al 
mismo tiempo, entre las regiones fue la latinoamericana la que registró la mayor desigualdad en la distribución del ingreso (Berry, 1998).

Nuestros esfuerzos por estimar la solidez de diversos eslabones en las cadenas A y B indican que aquellos entre el crecimiento económico y el desarrollo humano varían más en América Latina que a nivel mundial. El coeficiente de gasto social sale bien parado, pero el crecimiento del PIB no siempre se tradujo en una mejora significativa del desarrollo humano, lo que indica que en cada país se dieron situaciones concretas que afectaron la solidez de la cadena. Por otra parte, los eslabones de la cadena $\mathrm{B}$, que va de desarrollo humano a crecimiento económico, demostraron aproximarse más a los resultados de carácter global, con niveles iniciales de desarrollo humano que influyeron de manera significativa en el crecimiento económico. Respecto de ambas cadenas nos vimos limitados en lo que podíamos comprobar, ya que dispusimos de menos datos de países sobre algunas variables y de un menor número de observaciones.

Los casos de países analizados ilustran de qué manera las circunstancias concretas influyeron en la solidez de los diversos eslabones de las cadenas A y B. Nuestro estudio abarcó tres países que se situaron en el cuadrante de desempeño virtuoso en el período en su conjunto (Chile, Costa Rica y México) y tres que cayeron en el de desempeño vicioso (Guyana, Jamaica y Nicaragua).

Por lo que respecta a los tres casos exitosos, el crecimiento alto acompañado de un elevado coeficiente de gasto social se tradujo en mejoras del desarrollo humano (México en los años sesenta y setenta, y Chile en los sesenta). Un camino alternativo para alcanzar el éxito, ilustrado por Costa Rica, es el de lograr un crecimiento moderado y relativamente bien distribuido, acompañado de coeficientes de gasto social muy altos y adecuados coeficientes de prioridad. En el período intermedio (1975-1990), Chile mostró un tercer camino para llegar al éxito, que se caracteriza por gasto social muy bien focalizado, con crecimiento disparejo durante gran parte del período y un coeficiente de gasto social sólo moderado. Posteriormente, Chile se situó dentro del grupo de crecimiento elevado y adecuado coeficiente de gasto social.
Naturalmente, también hay muchos caminos que conducen al fracaso. En Nicaragua, durante el período de Somoza, el crecimiento acompañado de una distribución muy deficiente del ingreso privado y de los servicios sociales menoscabó apreciablemente la cadena A. Graves perturbaciones económicas y el hecho de que durante el ajuste no se protegiera a los sectores sociales explican el comportamiento relativamente deficiente del desarrollo humano en los años ochenta en Jamaica, durante gran parte del período de estudio en Guyana y durante los años noventa en Nicaragua. En el decenio de1980, la guerra y el embargo comercial contribuyeron de manera importante a socavar las mejoras en desarrollo humano de Nicaragua, además de que en todas las décadas se produjeron desastres naturales. La elevada deuda externa, acumulada como consecuencia de la guerra en el caso de Nicaragua, también obstaculizó los esfuerzos de desarrollo humano realizados en la Nicaragua de la posguerra, y en Guyana durante los años ochenta y noventa.

El estudio de la forma en que se comportaron los países decenio a decenio (véase más atrás el cuadro 1) confirma la impresión, a la cual ya habíamos llegado a nivel mundial, de que es preciso promover el desarrollo humano para poder situarse en un ciclo virtuoso de crecimiento económico y mejoramiento del desarrollo humano. Ningún país de América Latina logró pasar de un comportamiento sesgado en favor del crecimiento económico al ciclo virtuoso. Nuestras regresiones para América Latina revelan igual cosa, esto es, que aumentando el desarrollo humano efectivamente se mejora el crecimiento económico, aunque en este caso las mejoras del desarrollo económico no siempre dieron lugar a avances en el desarrollo humano. En consecuencia, nuestras conclusiones a nivel regional también son contrarias a la secuencia de políticas que se recomienda generalmente, esto es, que primero hay que generar crecimiento y que el desarrollo humano se dará por añadidura. Para terminar con una nota optimista, es posible que el aumento del gasto en el sector social registrado en América Latina en los años noventa prepare el camino para un mayor crecimiento en el decenio actual, en contraposición a las reducciones de ese gasto en los años ochenta que dificultaron el crecimiento y, en consecuencia, el desarrollo humano. 
Ainsworth, M., K. Beegle y A. Nyamete (1995): The Impact of Female Schooling on Fertility and Contraceptive Use: A Study of Fourteen Sub-Saharan Countries, LSMS working paper, $\mathrm{N}^{\circ}$ 110, Washington, D.C., Banco Mundial.

Alesina, A. y D. Rodrik (1994): Distributive politics and economic growth, Quarterly Journal of Economics, vol. 109, № 2 , Cambridge, Massachusetts, MIT Press.

Alesina, A. y R. Perotti (1994): The political economy of growth: A critical survey of the recent literature, The World Bank Economic Review, vol. 8, $\mathrm{N}^{\circ}$ 3, Washington, D.C., Banco Mundial.

Banco Mundial (1984): Trends in Developing Economies, Washington, D.C.

(varios años): World Development Indicators 2001, Washington, D.C.

Barro, R. (1991): Economic growth in a cross section of countries, Quarterly Journal of Economics, vol. 106, $\mathrm{N}^{\circ} 2$, Cambridge, Massachusetts, MIT Press.

Barro, R. y J. Lee (1993a): International comparison of educational attainment, Journal of Monetary Economics, vol. 32, $\mathrm{N}^{\circ} 3$, Amsterdam, Países Bajos, North-Holland Publishing Company. (1993b): Losers and winners in economic growth, en Banco Mundial, Proceedings of the World Bank Annual Conference on Development Economics, 1993, Washington, D.C., Banco Mundial.

Behrman, J. R. (1993): The economic rationale for investing in nutrition in developing countries, World Development, vol. 21, $\mathrm{N}^{\circ}$ 11, Oxford, Reino Unido, Pergamon Press.

(1994): Intrafamily distribution in developing countries, Pakistan Development Review, $\mathrm{N}^{\circ} 33$, Islamabad, Pakistán, TGE Pakistan Institute of Development Economics.

(1996): The impact of health and nutrition on education, The World Bank Research Observer, vol. 11, $\mathrm{N}^{\circ} 1$, Washington, D.C., Banco Mundial.

Berry, A. y M. Urrutia (1976): Income Distribution in Colombia, New Haven, Yale University Press.

Berry, A. (ed.) (1998): Poverty, Economic Reform and Income Distribution in Latin America, Boulder, Colorado, Lynne Rienner.

Birdsall, N., D. Ross y R. Sabot (1995): Inequality and growth reconsidered: Lessons from East Asia, The World Bank Economic Review, vol. 9, $\mathrm{N}^{\circ}$ 3, Washington, D.C., Banco Mundial.

Edwards, S. (1993): Openness, trade liberalization, and growth in developing countries, Journal of Economic Literature, vol. 31, $\mathrm{N}^{\mathrm{o}}$ 3, Nashville, Tennessee, American Economic Association.

FMI (Fondo Monetario Internacional) (varios años): Government Finance Statistics Yearbook, Washington, D.C.

Foster, A. D. y M. R. Rosenzweig (1994): Technical change and human resources and investments: Consequences of the green revolution, Philadelphia, Pennsylvania, University of Pennsylvania, inédito.

(1995): Learning by doing and learning from others: Human capital and technical change in agriculture, Journal of Political Economy, vol. 103, $\mathrm{N}^{\circ}$ 6, Chicago, Illinois, The University of Chicago.

Friedmann, S., N. Lustig y A. Legovini (1995): Mexico: Social spending and food subsidies during adjustment in the 1980s, en N. Lustig (ed.), Coping with Austerity: Poverty and Inequality in Latin America, Washington, D.C., The Brookings Institution.

Krueger, A. (1978): Foreign Trade Regimes and Economic Development: Liberalization Attempts and Consequences, Cambridge, Massachusetts, Ballinger.
Maddison, A. (1992): The Political Economy of Poverty, Equity and Growth: Brazil and Mexico, Washington, D.C., Banco Mundial.

Michaely, M. (1977): Exports and growth: An empirical investigation, Developing Economics, vol. 4, $\mathrm{N}^{\circ} 1$, Amsterdam, Países Bajos, North-Holland.

Persson, T. y G. Tabellini (1994): Is inequality harmful for growth, The American Economic Review, vol. 85, $\mathrm{N}^{\circ}$ 2, Nashville, Tennessee, American Economic Association.

PNUD (Programa de las Naciones Unidas para el Desarrollo) (1990): Desarrollo humano. Informe 1990, Santa Fe de Bogotá, Tercer Mundo Editores.

(1991): Desarrollo humano. Informe 1991, Santa Fe de Bogotá, Tercer Mundo Editores.

(2001): Desarrollo humano. Informe 2001, Santa Fe de Bogotá, Tercer Mundo Editores.

Psacharopoulos, G. (1994): Returns to investment in education: A global update, World Development, vol. 22, $\mathrm{N}^{\circ}$ 9, Oxford, Reino Unido, Pergamon Press.

Psacharopoulos, G. y otros (1992): Poverty and Income Distribution in Latin America: The Story of the 1980s, Washington, D.C., Banco Mundial.

Raczynski, D. (1987): Política social, pobreza y grupos vulnerables: la infancia en Chile, en G. Cornia, R. Jolly y F. Stewart (eds.), Ajuste con rostro humano, vol. 2, Madrid, Siglo XXI de España Editores.

Ram, R. (1985): Exports and economic growth: Some additional evidence, Economic Development and Cultural Change, vol. 33, $N^{\circ} 2$, Chicago, Illinois, The University of Chicago Press.

Rana, P. (1988): Exports, policy changes and economic growth in developing countries after the 1973 oil shock, Developing Economics, vol. 28, $\mathrm{N}^{\circ} 3$, Amsterdam, Países Bajos, NorthHolland.

Ranis, G., F. Stewart y A. Ramírez (2000): Economic growth and human development, World Development, vol. 28, $\mathrm{N}^{\circ} 2$, Oxford, Reino Unido, Pergamon Press.

Riddell, R. y otros (1995): Non-governmental Organizations and Rural Poverty Alleviation, Nueva York, Oxford University Press.

Riveros, L. (1998): Chile's structural adjustment: Relevant policy lessons for Latin America, en A. Berry (ed.), Poverty, Economic Reform and Income Distribution in Latin America, Boulder, Colorado, Reiner.

Rosenzweig, M. R. (1995): Why are there returns to schooling?, The American Economic Review, vol. 85, $\mathrm{N}^{\circ}$ 2, Nashville, Tennessee, American Economic Association.

Schultz, T. W. (1975): The value of the ability to deal with disequilibria, Journal of Economic Literature, vol. 13, $\mathrm{N}^{\circ} 3$, Nashville, Tennessee, American Economic Association.

Schultz, T. P. y A. Tansel (1993): Measurement of Returns to Adult Health, LSMS working paper, $\mathrm{N}^{\circ} 95$, Washington, D.C., Banco Mundial.

Thorp, R. (1998): Progreso, pobreza y exclusión: una historia económica de América Latina en el siglo XX, Washington, D.C., Banco Interamericano de Desarrollo (BID).

Welch, F. (1970): Education in production, Journal of Political Economy, vol. 78, $\mathrm{N}^{\circ} 1$, Chicago, Illinois, The University of Chicago Press.

Wood, A. (1994): North-South Trade, Employment and Inequality: Changing Fortunes in a Skill-Driven World, Oxford, Reino Unido, Oxford University Press. 